\section{SOCIAL AND INDUSTRIAL INSURANCE IN GREAT BRITAIN}

\begin{abstract}
A LMOST two years after the publication of Sir William Beveridge's report on Social Insurance and Allied Services, the Government has issued two White Papers, Part 1 dealing with its proposals for social insurance generally (except for industrial injury) and for family allowances, and Part 2 with proposals for replacing the existing system of workmen's compensation by a new scheme of industrial injury insurance. The whole scheme follows the lines indicated by Sir William Beveridge more closely than the prolonged delay had led many to expect.
\end{abstract}

\section{Social Insurance}

In introducing the proposals for social insurance (Part 1)* the White Paper states that the Government accepts as necessary prerequisites to an improved and comprehensive plan of social insurance the three assumptions on which the Beveridge plan was based : institution of a scheme of children's allowances; framing of a comprehensive health service; and the avoidance of mass unemployment. Proposals for a national health service have already been published, and the Government's policy for maintaining a high and stable level of employment after the War has been set forth in the White Paper on Employment Policy. Those for a scheme of family allowances are included in the present paper.

These proposals are based upon two principles: first that nothing shouid be done to remove from parents the responsibility of maintaining their children ; and second, that it is in the national interest for the State to help parents to discharge that responsibility properly. The scheme is not intended to provide full maintenance for each child but is a general contribution to the needs of families with children. This purpose, in the Government's view, can best be attained if a substantial part of the benefit is given in kind, and the school meals and milk services will therefore be extended to make them available to pupils in primary and secondary schools in receipt of grant from the Ministry of Education or the Scottish Education Department. These benefits in kind will be free of cost to the parents and will be available to all children in a family attending school, including the first.

The cost to public funds of supplying meals and milk to children at school when the service has reached its full development is estimated at about $£ 60$ millions a year. While accepting the argument in the Beveridge Report that children's allowances should be non-contributory and met wholly out of taxation, and that no allowance should be paid in respect of the first child, the Government rejects the rate of $8 s$. a week suggested by Sir William Beveridge and proposes a weekly cash allowance of $5 s$. for all children after the first below school-leaving age and remaining at school until July 31 following their sixteenth birthday. When the parent is receiving benefit, $5 s$. will be added to the benefit in respect of the first child.

With the exception of this family allowance scheme, the Government has adhered to the principle that freedom from want must be achieved in the first instance by social insurance : benefits must be

* Social Insurance. Part 1. (Cmd, 6550.) Pp. 64. (London: H.M. Stationery Office, 1944.) $6 d$. net. earned by contributions. It has also decided not only to increase the range and amount of benefits provided, but that the scheme as a whole shall embrace the entire population. Of the six fundamental principles on which the Beveridge plan was based, the Government has adopted five : flat rate of contribution; flat rate of subsistence benefit; unification of administrative responsibility; comprehensiveness; and classification. There has been no attempt to vary contributions with the earnings of those who make them: broadly, the principle adopted has been that of equal benefits for equal contributions. Contributors and beneficiaries are classified into six groups, differing in respect of the benefits they need and the contributions they must make to receive them. Adopting the principle that the administration of a single, comprehensive, universal scheme of social insurance must be unified and that the various unco-ordinated sections of the system of to-day must be brought within a single administrative framework, the Government proposes the establishment of a Ministry of Social Insurance responsible for the whole of social insurance. The administration of assistance will be kept separate from that of insurance, though the Minister of Social Insurance will be responsible to Parliament for both. The present responsibilities of public assistance authorities for the payment of assistance in cash will be transferred entirely to the Assistance Board.

The Government has not accepted the sixth principle of adequacy of benefit. In fixing the rates of benefit, the Government considered whether it would be practicable to adopt a subsistence basis for benefits, but has rejected this as impracticable on the ground that the linking of benefit to subsistence-rates might involve the frequent variation of benefit-rates in accordance with the cost of living, and also that social insurance must necessarily deal in averages of need and requirement. A high level of benefit must mean a high level of contribution, and the Government concludes that the right objective is a rate of benefit which provides a reasonable insurance against want and at the same time takes account of the maximum contribution which the great body of contributors can properly be asked to bear. There still remains the individual's opportunity to achieve for himself in sickness, old age, and other conditions of difficulty a standard of comfort and amenity which it is no part of a compulsory scheme of social insurance to provide. In reserve there must remain a scheme of national assistance designed to fill the inevitable gaps left by insurance, and to supplement them where an examination of individual needs shows that supplement is necessary. There is no reference to a unified means test as advocated in the Beveridge Report, but the supercession advocated in the latter of the present system of approved societies is accepted: the Government concludes that it is not practicable to retain 'approved societies' either as independent financial units or as agents in the administration of the scheme. The considerations leading the Government to this conclusion and the alternative proposals of the Report, together with the wider proposals submitted on behalf of the approved societies, are summarized in Appendix II of the White Paper.

The scheme proposed by the Government is compulsory and includes everybody. The population will be divided into six classes: employees; the self-employed; housewives; adults who do not earn; children; and people over working age. It thus applies to large categories not hitherto covered 
by insurance; for example; those living on earnings gained otherwise than by salary or wages, or on earnings above $£ 420$ a year or on private income, and those employed in professions or industries hitherto specially excepted. Each insured person will pay a single weekly contribution for all benefits in the form of one stamp on a single document. For employed persons the stamp will also include the contribution for insurance against industrial injury. The first, second and fourth will be the contributing classes, and the rates of weekly contribution for persons over 18 (covering for Class I the benefits under the Industrial Injury Insurance Scheme as well as the Social Insurance Scheme) will be:

\begin{tabular}{|c|c|c|c|c|c|}
\hline & & Class I & & & \\
\hline & $\begin{array}{l}\text { Insured } \\
\text { Person } \\
\text { s. d. }\end{array}$ & $\begin{array}{l}\text { Employer } \\
\text { s. d. }\end{array}$ & $\begin{array}{l}\text { Total } \\
\text { s. d. }\end{array}$ & s. d. & s. d. \\
\hline $\begin{array}{l}\text { Aged } 18 \text { and over } \\
\text { Women } 16-18\end{array}$ & $\begin{array}{cc}3 & 10 \\
2 & 5\end{array}$ & $\begin{array}{ll}3 & 1 \\
2 & 1\end{array}$ & $\begin{array}{rr}6 & 11 \\
4 & 6\end{array}$ & $\begin{array}{ll}4 & 2 \\
2 & 9\end{array}$ & \\
\hline $\begin{array}{l}\text { Aged } 18 \text { and over } \\
, \quad 16-18\end{array}$ & $\begin{array}{ll}3 & 0 \\
2 & 0\end{array}$ & $\begin{array}{ll}2 & 5 \\
1 & 7\end{array}$ & $\begin{array}{ll}5 & 5 \\
3 & 7\end{array}$ & $\begin{array}{ll}3 & 6 \\
2 & 5\end{array}$ & $\begin{array}{rr}2 & 8 \\
1 & 10\end{array}$ \\
\hline
\end{tabular}

There will be a standard rate of benefit of $40 \mathrm{~s}$. a week for a married couple and $24 s$. for a single man or woman, with lower rates for those less than 18 . Sickness benefit will end after three years of continuous disability, and invalidity benefit at the standard retirement pension will be substituted. Unemployment benefit will be paid up to a limit of thirty weeks in a continuous period, together with additional days where the contributor has a good record of employment. After the end of either benefit, further contributions must be paid before an insured person can re-qualify for benefit. Special allowances at a higher rate will be available to persons undergoing a course of approved training, but such training allowances will not form part of the social insurance scheme but will be paid out of taxation. There is no condition, as in the Beveridge plan, of unemployment benefit being subject after a certain period to attendance at a work or training centre, and this, like the limitation of benefit, is a marked break from Sir William Beveridge's proposals.

With regard to the self-employed, the difficulties of securing effective control over the payment of benefit are emphasized, as in the Beveridge Report, but the Government proposes to pay benefit to Class II contributors after four instead of after thirteen weeks, and to excuse payment of contributions during those four weeks. An additional allowance of $16 s$. a week will be paid to those on single benefit who have an adult dependant. There will be a standard rate of retirement pension of $35 \mathrm{~s}$. for a married couple and 20s. for a single person. These rates will take effect from the commencement of the scheme instead of starting at 25s. and 14s., respectively, and increasing to the full rate of $40 \mathrm{~s}$. and $24 \mathrm{~s}$. after twenty years as recommended in the Beveridge Report. The pensionable age will be sixty-five for men and sixty for women, but the joint pension will become payable when the husband qualifies, provided that if the wife is less than sixty years old, she is not gainfully occupied. Pensions will be paid only to those who have retired and will be reduced if more than $20 s$. weekly is earned during retirement. They will also depend on contributions paid during the working life of the applicant, and will be reduced when the contribution record shows a deficiency. Pensions will be increased by $2 s$. a week (joint) and 1s. (single) for each year of work after retirement age. Special arrangements will be made covering persons already pensioned or insured when the scheme comes into operation.

For married women, additional benefits will be available, subject to certain qualifying conditions, in a maternity grant of $£ 4$, maternity benefit at the rate of $36 s$. a week for thirteen weeks for gainfully occupied women, provided that occupation is given up for that period, or for women not eligible for maternity benefit, an attendant's allowance of $£ 1$ a week for four weeks. Special provisions will enable married women to insure for a personal retirement pension of 20s. a week in lieu of their share in a joint pension, and enabling married women earning more than $20 \mathrm{~s}$. a week to insure for sickness benefit at the rate of 16s. a week and unemployment benefit at 20s. a week. The main provisions for widows will be a benefit of $36 s$. a week, with 5s, added for the first child, during the first thirteen weeks of widowhood. Thereafter, if there is a dependent child, a guardian's benefit of 24s. a week, with 5s. added for the first or only child, and a widow's pension of $20 \mathrm{~s}$. a week to widows who are fifty or over when the husband dies or when the children cease to be dependent, provided ten years have elapsed since the marriage. These benefits will terminate on remarriage, and the last two will be reduced for substantial earnings.

Death grants will be paid at the rates recommended in the Beveridge Report according to the age at death, but an age limit of sixty-five instead of sixty is proposed, when one grant will be paid at the beginning of the scheme, and for persons then between fifty-five and sixty-five the grant will be $£ 10$. Such questions as insurance for indirect expenses connected with funerals are reserved for separate examination. Sickness and invalidity benefit, maternity benefit, widow's benefit, guardian's benefit, widow's pension and retirement pension will be reduced by $10 s$. a week during maintenance in hospital after the first twenty-eight days of such maintenance. Not more than any one social insurance benefit or pension will be payable to an individual at any one time.

Apart from the question of workmen's compensation, the Government in its scheme has accepted outright sixteen out of the twenty-three changes proposed in the Beveridge Report; and with modification or reserve two of the others. Essentially the scheme may be described as on a practical basis. The refusal to make disability benefit indefinite in duration or unemployment benefit at full rate indefinite in duration but conditional on attendance at a work or training centre after a limited period, like the rejection of a subsistence basis for benefits, shows that the Government has not adopted the basic philosophy of the Beveridge Report; but there can only be the warmest welcome for proposals which sweep away so many anomalies, and simplify and unify administration and rates of benefit and contribution. It will be noted that the administrative organization outlined is framed to meet the position at the beginning of the new scheme, and that it is proposed to review the position when the scheme is in operation and administrative policy clearly defined and established.

\section{Industrial Insurance}

Whatever slight disappointment may be felt in some quarters with the Government's proposals for social insurance as lacking the boldness of the original Beveridge Report, and keeping more strictly to the 
actual abolition of want, no charge of lack of boldness can be brought against the proposals for an industrial injury insurance scheme outlined in the White Paper issued as 'Social Insurance. Part 2: Workmen's Compensation"*. The need for radical reform of the present situation is frankly accepted, and the proposals advanced are in some respects an improvement on the Beveridge scheme. They are intended to avoid the main weaknesses and difficulties of the existing system and to remove workmen's compensation from the atmosphere of controversy and conflict with which it has been surrounded and establish it on a happier and sounder foundation.

The White Paper gives first a concise summary of the present system of workmen's compensation in Great Britain, first established in 1897, followed by a survey of the proposals on this question in the Beveridge Report and a concise statement of the Government's views. Generally, the Government endorses the criticisms of the existing system made in that report. In particular, it considers that the Beveridge scheme is too complicated and allows too much scope for contention between the workman (or his trade union) and the employer (or the insurance company or mutual association with which he is insured); it thus tends to retard the workman's recovery and to prejudice good relations between him and his employer. The Government considers it essential to provide that, in future, claims should be made on an independent authority and settled by a procedure less liable to give rise to friction. Accordingly it reaches the general conclusion that the present system should be replaced by a new scheme, the general structure of which should be based on the accepted principles of social insurance.

Proceeding on this basis, the Government agrees with the proposals in the Beveridge Report that the new scheme, broadly speaking, should apply to all persons working under a contract of service, including non-manual workers, and without any income limit; that the cost should be borne by a central fund main. tained by contributions from employers and workmen, with a contribution from the Exchequer; that claims should be dealt with by administrative rather than legal procedure; and that the responsibility for the general administration and supervision of the working of the scheme should rest on the authority responsible for the general scheme of social insurance. It is unable, however, to accept four of the main proposals of the Beveridge Report for the reasons indicated below.

First, the Government does not think it right to limit special rates of benefit for long-term disability to cases of more than thirteen weeks duration. Such cases constitute not more than 10 per cent of the total, and the Government thinks the advantage claimed for unification of rates during an initial period is exaggerated. Secondly, the proposal to relate industrial pensions for long-term disability to the earmings of the workman before the accident in cases of total incapacity, and to his earnings both before and after the accident in cases of partial incapacity, is regarded as contravening the principle that there should be differentiation in benefits only according to family responsibilities, and that subject to provision for such responsibilities, there should be uniform flat rates of benefit in return for uniform flat rates of contribution. Further, the assessment of

- Social Insurance. Part 2: Workmen's Compensation. Proposals for an Industrial Injury Insurance Scheme. (Cmd. 655i.) Pp. 32. (London: H.M. Stationery Office, 1944.) 3d. net. workmen's compensation by reference to earnings has given rise to serious difficulties and objections which are considered in some detail in the White Paper.

The Government therefore proposes to adopt two entirely new features for the assessment of industrial pensions : (a) to provide, in accordance with the generally accepted principle of social insurance, uniform flat rates of pension without regard to pre. accident earnings, but taking account of family responsibilities; and $(b)$ to give benefit according to the degree of disablement due to the injury in the same way as is done under war pensions schemes, through assessment by a medical board of the condition of the workman resulting from the injury as compared with the condition of a normal healthy person of the same age and sex. This principle has the advantage of getting rid of the distinction hitherto drawn between total and partial incapacity for work, and giving the workman who has suffered an injury causing permanent or prolonged disablement a pension commensurate with the assessed degree of disablement, irrespective of his earning capacity. It eliminates as a cause of dispute the questions whether or to what extent the workman has recovered his earning capacity. It removes the grievance that an improvement in earning capacity results in an automatic reduction of compensation, and avoids any ground for suspicion on the part of the workman that he is being pressed to return to unsuitable work with a view to such reduction, and the fear that if he returns to work he will jeopardize his right to further compensation. It should also remove any hesitation he may feel in submitting to a course of rehabilitation treatment and thus promote a speedier recovery, while it helps to meet the complaint that no compensation is paid for mutilation or disfigurement except in so far as it causes loss of earning capacity.

Thirdly, the Government does not agree with the proposal in the Beveridge Report that special provision in fatal cases resulting from industrial accident or disease should be by way of the grant of a lump sum. Such payments, even if administered under strict control, are not a satisfactory method of assuring an income, and the Government considers that provision for dependants in fatal cases should be by way of pension or weekly allowance. Fourthly, the Government does not accept the proposal that a substantial part of the fund for payment of benefits should be found by means of a special levy on employers in the hazardous industries. This proposal constitutes a departure from the complete pooling of risks adopted generally in other branches of social insurance. "Hazardous industries are not hazardous because employers in them are less active in the prevention of accidents than other employers, or because the workmen in those industries are less careful than other workmen. They are hazardous because of the nature of the employment and the inherent risks." The Government questions the value of the incentive to the prevention of accidents ascribed to the merit rating system suggested in the Beveridgle Report, and considers that for further progress in this matter we should look to the development of the standards set up under the factories, mines and other safety enactments, and to the increase of co-operation between employers and workmen. On the other hand, the Government would welcome the establishment of joint bodies for dealing with safety questions-either statutory or voluntary -in all industries where there are substantial risks 
of industrial accident and disease. It also agrees with the recommendation in the Beveridge Report that an inquiry is desirable into the relation, both in industrial and non-industrial cases, between claims to security benefit and claims for damages in respect of personal injury caused by negligence, and also a review of the law governing the liability of employers and third parties to pay damages or compensation to workmen, or their legal representatives and dependants, independently of the provision for them proposed in the new scheme; the Government has set up for this purpose a committee with comprehensive terms of reference under the chairmanship of Sir Walter Monckton.

The remaining features of this new scheme to treat workmen's compensation not as part of the law of employer's liability but as a social service may be briefly summarized as follows. The scheme will be comprehensive, will not provide for 'contracting out' schemes and will apply to accidents arising out of, and in the course of, employment and to specified industrial diseases. The liability, instead of being on the individual employer, will be placed upon a central fund out of which all benefits, both in disablement and fatal cases, and administrative charges will be paid. The fund will be maintained by weekly contributions from employers and workmen collected by stamp, with a contribution from the Exchequer. The weekly rates of contribution will be $6 d$. for adult men and $4 d$. for women, to be shared equally between the employer and workmen, with half these rates for juveniles. Benefits will not depend on a contribution qualification. The scheme will be under the general charge of the Minister of Social Insurance, with an advisory committee or council, on which employers and workmen will be equally represented, to advise the Minister on important matters of policy and administration referred to them. Employers and workmen will be equally represented on the local appeal tribunals.

The present procedure by which the workmen's claims against employers are subject to appeals to courts of law will be superseded by a system under which claims will be dealt with by a pensions ofticer, subject to rights of appeal to local tribunals, and further rights of appeal to an industrial injury insurance commissioner whose decision will be final. In disablement cases the benefits will be at uniform flat rates. They will consist of an industrial injury allowance payable for an initial period while the workman is incapacitated for work, to be replaced, where the disablement is likely to be permanent or prolonged, by an industrial pension which will be supplemented by a special allowance if the pensioner is unemployable. Allowances will be given for family responsibilities, and treatment allowances and allowance for constant treatment in certain circumstances. No provision will be made for commutation of the pension by a lump sum payment, but where the injury results in only a minor degree of disability, provision will be made for a final settlement by an award of a gratuity or of a temporary allowance at a special rate with or without a final gratuity. In fatal cases the scheme provides for payment of a pension to the widow with an allowance for the first child, and a higher rate of allowance where the first child is an orphan. Provision will be made, in certain circumstances, for payment of a pension to one or both parents, or where no widow's or parent's pension is payable, to one adult dependent member of the deceased workman's family.

\section{PROBLEMS OF MODERN PHYSICS* $\dagger$}

\author{
BY PROF. J. FRENKEL
}

\section{The Atomic Nuclei, Elementary Particles and the Nature of Matter}

Nuclear physics emerged as a new independent science when, ten years ago, Cockcroft and Walton, working on a suggestion by Rutherford, first used protons artificially accelerated to immense velocities for bombarding other heavier atoms. Before that time, work of this kind had only been done with the help of radioactive substances, atoms of which are transmuted spontaneously without any outside agent, with the expulsion of alpha-particles (that is, helium nuclei) or beta-particles (fast electrons). These alpha- and beta-particles can be used to transmute artificially stable atomic nuclei. This method still has its value, and with its help (by bom. barding beryllium with alpha-particles emitted in the natural radioactive disintegration of polonium) it was shown that besides protons (hydrogen nuclei) complex nuclei contain also neutrons. These are particles similar in mass to protons but having no electric charge. To obtain neutrons in the free state, nuclear physics has begun to use clusters of protons or deutons (nuclei of heavy hydrogen). These are accelerated to speeds corresponding to energies of some tens of millions of volts, by special apparatus such as the cyclotron, which was invented in the United States by E. O. Lawrence in 1930.

By such methods it has been possible to cause and study a large number of nuclear reactions of the type

$$
A+B \rightarrow C+D
$$

where $A$ and $B$ are the initial nuclei and $C$ and $D$ the resulting ones. 'These 'alchemical' reactions are in many respects similar to ordinary chemical reactions ; but they differ above all in the very much larger energy balance involved (as a matter of fact it is some million times larger). As a rule, one of the reacting particles $(A$ or $B$ ) is a very simple nucleus, such as a proton or deuton, or in the limiting case a helium nucleus, and the other is a complex nucleus. Thus the reaction $A+B \rightarrow C+D$ is usually treated as the artificial disintegration of the nucleus $A$ by the particle $B$ (a proton, for example), which leads to the expulsion from it of the particle $D$ (say a neutron). Really this reaction results in the union of $A$ and $B$ into a complex nucleus $(A B)$, which is in an unstable, excited state, and so spontaneously splits up: $A B \rightarrow O+D$.

Like chemical reactions, these transformations can be either endothermic or exothermic. If $A$ and $B$ have a charge of the same sign, the stage $A+B \rightarrow A B$ requires a definite amount of energy for its initiation, and this is supplied by the kinetic energy of the bombarding particle $B$. This energy is needed to overcome the coulomb repulsion between the two particles. It is as if the nucleus $A$ were surrounded by a protective rampart in the form of a "potential barrier' of tens of millions of volts, and if the motion of material particles were governed by the classical laws of mechanics then the particle $B$ would have to have kinetic energy at least as great as the height of this potential barrier in order to get past it. In

\footnotetext{
* Translated by E. R. Holmberg from Vestnik Acad.Sci., U.S.S.R., 4-5 (1943), made available by courtesy of the Science Section of the Society for Cultural Relations with the U.S.S.R.

t Continued from page 421 .
} 